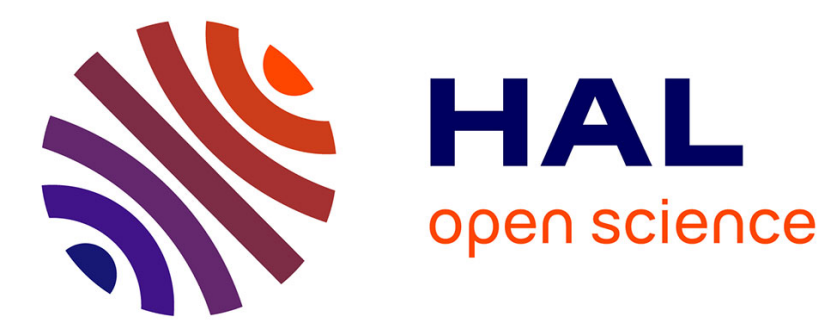

\title{
Preface to Multiscale Simulation in Geochemistry
}

\author{
Xiandong Liu, Christophe Tournassat, Carl I. Steefel
}

\section{To cite this version:}

Xiandong Liu, Christophe Tournassat, Carl I. Steefel. Preface to Multiscale Simulation in Geochemistry. Geochimica et Cosmochimica Acta, 2020, 291, pp.1-4. 10.1016/j.gca.2020.09.011 . insu02942528

\section{HAL Id: insu-02942528 \\ https://hal-insu.archives-ouvertes.fr/insu-02942528}

Submitted on 18 Sep 2020

HAL is a multi-disciplinary open access archive for the deposit and dissemination of scientific research documents, whether they are published or not. The documents may come from teaching and research institutions in France or abroad, or from public or private research centers.
L'archive ouverte pluridisciplinaire HAL, est destinée au dépôt et à la diffusion de documents scientifiques de niveau recherche, publiés ou non, émanant des établissements d'enseignement et de recherche français ou étrangers, des laboratoires publics ou privés. 


\section{Journal Pre-proofs}

Editorial

Preface to Multiscale Simulation in Geochemistry

Xiandong Liu, Christophe Tournassat, Carl I. Steefel

PII:

S0016-7037(20)30572-X

DOI:

https://doi.org/10.1016/j.gca.2020.09.011

Reference:

GCA 11917

To appear in:

Geochimica et Cosmochimica Acta

Please cite this article as: Liu, X., Tournassat, C., Steefel, C.I., Preface to Multiscale Simulation in Geochemistry, Geochimica et Cosmochimica Acta (2020), doi: https://doi.org/10.1016/j.gca.2020.09.011

This is a PDF file of an article that has undergone enhancements after acceptance, such as the addition of a cover page and metadata, and formatting for readability, but it is not yet the definitive version of record. This version will undergo additional copyediting, typesetting and review before it is published in its final form, but we are providing this version to give early visibility of the article. Please note that, during the production process, errors may be discovered which could affect the content, and all legal disclaimers that apply to the journal pertain.

(C) 2020 Published by Elsevier Ltd. 


\section{Preface to Multiscale Simulation in Geochemistry}

\section{Xiandong Liu ${ }^{\mathrm{a}}$, Christophe Tournassat $^{\mathrm{b}, \mathrm{c}, \mathrm{d}}$, and Carl I. Steefel ${ }^{\mathrm{d}}$}

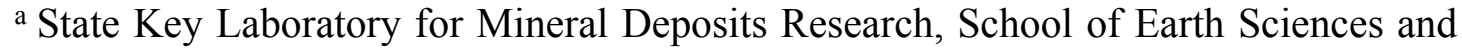
Engineering, Nanjing University, Nanjing, Jiangsu 210023, China

b BRGM, Orléans, France,

'Université d'Orléans-CNRS/INSU-BRGM, Institut des Sciences de la Terre d'Orléans, Orléans, France

d Lawrence Berkeley National Laboratory, Berkeley, CA, USA

Email: xiandongliu@nju.edu.cn; C.Tournassat@lbl.gov; CISteefel@lbl.gov

The use of numerical modeling has grown to be an indispensable tool for both experiment and theory since the invention of the first modern computer ENIAC in the 1940s. Computer simulation has been successfully applied to understand and predict physical and chemical properties of engineered and natural systems in almost all disciplines. At the smallest scale, atomistic/molecular simulations have been successfully applied in various fields of research, including geochemistry. Its powerful prediction ability stems from the fact that the computation is carried out at microscopic scales and relies on fundamental physics principles. First principles molecular modeling is nearly free of any empirical parameters. These techniques have proven extremely useful in the study of structures and reactions of small molecules, solids, and surfaces. However, macroscopic or continuum modeling, which typically includes at least some empirical or fitted parameters, cannot be replaced completely by first principles calculations because of many factors, including the computational cost of the microscopic approaches. To address longer length and time scales than is possible with microscopic modeling, the information provided by these simulations must be translated into useful upscaled parameters for larger scale modeling. To this end, multiscale simulation is needed to solve scientific problems that show distinct features at different temporal and/or spatial scales, i.e. that show separation of scales. Multiscale simulation is then based on the techniques that bridge different scales of such complex systems.

Multiscale simulation has been very successful in the fields of physics, chemistry, and biological science. A remarkable event is the Nobel Prize in Chemistry for 2013 awarded to Martin Karplus, Michael Levitt and Arieh Warshel "for the development of multiscale models for complex chemical systems". Multiscale modeling, however, remains an emerging approach in the earth sciences. The problems faced in the earth sciences may be even more complicated than those encountered in the more fundamental sciences because of the intrinsic complexity of natural solutions and 
minerals, but also because of the inherent and often imperfectly described heterogeneity of natural earth materials. The problems that geochemistry faces are typically multiscale, ranging from nanometer to planetary scales in size and from picoseconds to billions of years in time. The features and properties of earth systems (e.g., sedimentary basins or igneous and metamorphic rock provinces) are typically tens of orders of magnitude larger than typical microscopic lengths. They also exhibit ultra-slow evolution on time scales that are tens of order longer than typical scales explored in chemistry and physics. Therefore, new concepts, models and effective simulation methods that link different length and time scales are needed for applications in geochemistry.

This GCA special issue "Multiscale Simulation in Geochemistry" intends to highlight the recent progress in the study of multiscale simulation in the field of geochemistry. We assembled a group of researchers currently active in using/developing multiscale simulation to understand geochemical problems. The articles include contributors from numerous countries, and represent a diversity of important topics and simulation methods. The computational methods covered scales ranging from microscopic to macroscopic modeling, i.e. from first-principle molecular computations to continuum-scale reactive transport modeling, as well as hybrid modeling of molecular-macroscopic systems. The emerging use of machine-learning methods was also illustrated in two contributions that parameterize atomic scale simulations, and upscale geomaterials microscopic properties to continuum-scale modeling. Finally, the topics explored in these contributions span a wide range of geochemical topics applicable to environments from the Earth's core to its surface, including: solid-liquid partitioning under Earth's core conditions (Zhang et al., 2020b), chemical geodynamics of the mantle (Zhang and Liu, 2020), recycling of noble gas in the subduction zones (Wang et al., 2020), thermodynamics of hydrothermal fluids (Mei et al., 2020), interfacial and structural properties of clay and (Fe, $\mathrm{Mn}$ ) oxide materials (Bylaska et al., 2020; Newton and Kwon, 2020; Zhang et al., 2020a), and a machine learning-based framework for coupling and upscaling of reactive transport processes and parameters across spatial scales (Prasianakis et al., 2020). These papers are briefly introduced in the following.

Sulfur is one of the major candidates for the light elements in the Earth's core and its partitioning across the inner core boundary may be important to drive the magnetic field related convection in the outer core. To obtain the accurate partition coefficients of sulfur under Earth's core conditions, which is still unclear from experiments, Zhang et al. (Zhang et al., 2020b) present a new framework based on a machine learning approach trained on high quality quantum mechanics data. By extending the data to higher T-P conditions unavailable with current experimental approaches, they show 
that the partition coefficient of sulfur is essentially insensitive to temperatures and pressures. Technically, Zhang et al. (2020b) provide a new approach to efficiently and accurately predict the chemical potential of mixtures that is central for the thermodynamic equilibrium problems in geochemistry, and can thus be applicable to a variety of complex problems involving equilibrium between multiple phases.

One important hypothesis of chemical geodynamics is that isotope anomalies found in mantle-derived samples are the result of different sources rather than chemical processes. This hypothesis denies the possible origins of isotope anomaly from fractionation/differentiation processes at high temperatures. To determine whether small mass-independent isotope fractionations can be magnified to observed isotope anomalies, Zhang and Liu (2020) designed a multi-stage closed-system melting and crystallization evolution model and conducted Monte Carlo (MC) simulations taking quantum mechanics computed parameters of $\mathrm{W}$ and $\mathrm{O}$ isotopes as the input. Their results confirmed that there is an amplification effect during such multi-stage evolution process that leads to the final isotope fractionations scaled as the total number of melting/crystallization processes for a specific component during the simulation. This work opens new perspectives for the origin of isotope anomalies observed in mantlederived samples.

The knowledge of the retention of noble gases in minerals in the subduction zone is fundamental to assess quantitatively the mantle dynamics and the evolution of the atmosphere. Wang et al. (2020) studied the diffusion of noble gases ( $\mathrm{He}, \mathrm{Ne}, \mathrm{Ar}, \mathrm{Kr}$ and $\mathrm{Xe}$ ) in hydrous minerals present in subduction zone materials by combining density functional theory (DFT) and diffusive loss modeling. They concluded that the oceanic crust and the lithospheric mantle of the subduction slab play different roles in delivering noble gases into the mantle. While all dissolved $\mathrm{Ar}, \mathrm{Kr}, \mathrm{Xe}$ and part of the $\mathrm{Ne}$ can be entrained by the serpentine-dominated lithospheric mantle, noble gases in the amphibole-enriched oceanic crust should be characterized by fractionated noble gas signature with concentrations in the crust following the order the order $\mathrm{Ne}<\mathrm{Ar}<\mathrm{Kr}<$ Xe.

The knowledge of thermodynamic properties for aqueous gold complexes is crucial for the understanding of the formation of hydrothermal gold deposits. Mei et al. (2020) extrapolated the formation constants of $\mathrm{Au}^{+}-\mathrm{OH}^{-} / \mathrm{NH}_{3} / \mathrm{H}_{2} \mathrm{O}$ complexes computed with first principles molecular dynamics (FPMD) simulations to a wide T-P range. Then, these thermodynamic data were used assess the contribution of $\mathrm{Au}(\mathrm{I})-\mathrm{NH}_{3}$ complexes to the solubility of gold in hydrothermal fluids. The authors showed that gold can be transported as $\mathrm{Au}^{+}-\mathrm{OH}^{-} / \mathrm{NH}_{3}$ complexes in sulfur-poor and ammonia-rich hydrothermal fluids, while the complex $\left[\mathrm{Au}\left(\mathrm{NH}_{3}\right)(\mathrm{OH})\right]^{0}{ }_{(\mathrm{aq})}$ may be responsible for a very limited transport of gold in near-neutral to alkaline sulfur-containing fluids under extremely 
reduced conditions.

Redox cycling of $\mathrm{Fe}^{2+}-\mathrm{Fe}^{3+}$ in iron bearing oxides, clays, and micas is important in a number of geochemical and environmental processes. The estimation of electron transfer rates in these minerals is thus a necessary step to understand and quantify, at a fundamental level, e.g. the fate and transport of redox sensitive toxic elements and radionuclides, cellular metabolism, and the degradation of organics. Bylaska et al. (2020) used a first principles technique based on plane wave DFT to model the small polaron hopping between edge-sharing octahedra sites in hematite (e- polaron), goethite (e- polaron) and annite ( $\mathrm{h}^{+}$polaron) bulk structures. The results confirmed the existence of small polarons in the three minerals, as well as the adiabatic nature of the electron transfer (ET) reactions. The authors showed that the method is accurate for computing the key gradients for charactering ET reactions, including the electron-transfer coupling matrix element $\left(\mathrm{V}_{\mathrm{AB}}\right)$, and the electron transfer transmission factor $\left(\kappa_{\mathrm{el}}\right)$, and therefore, it can be applied on a wide range of geochemical problems involving ET reaction.

Manganese oxide minerals serve as important controls in the geochemical cycle of many elements in soils and sediments. These minerals exhibit a range of tunnel and layer structures that are difficult to characterize unambiguously because of their dynamic transformations associated to variations in chemical composition and structural vacancies. The modeling of these structures and of their reactivity at the molecular scale provides useful information to study their reactivity as a function of environmental conditions. By using DFT calculations, Newton and Kwon (2020) extended an existing force field to describe phyllomanganates that include $\delta-\mathrm{MnO}_{2}$ and hydrous and anhydrous tunnel structures with octahedral vacancy contents up to $20 \%$. By carrying out large-scale classical molecular dynamics simulations with this force field, the authors provided new insights into the $\mathrm{Mg}$ site occupancy in todorokite and the $\mathrm{Zn}$ coordination in vernadite. Together with the prior tests, the authors showed that their force field is a powerful tool for the investigation of structural and dynamic properties of phyllo- and tecto-manganates.

Clay-soil organic matter (SOM) associations play important roles in processes in the critical zone, such as carbon sequestration, contaminants retention, and nutrients uptake. Zhang et al. (2020a) investigated clay-SOM interactions by combining FPMD and CMD techniques. FPMD was used to quantify the binding mechanisms of reactive SOM groups (including carboxylate, phosphate, quinone species and ammonium groups) on clay surfaces and to derive parameters for the bonding of the reactive groups on clay edge surfaces. By combining the derived parameters with other force fields, CMD simulations were carried out to investigate the structures of large models of claySOM associations under dry and wet conditions. Building on these results, the authors proposed a procedure for constructing realistic molecular models for soils. 
Natural mass transport phenomena are driven by thermal, chemical, mechanical and hydraulic gradients, but the implementation of process coupling for these complex systems is scale dependent. Effective phenomenological simulation parameters often rely on complementary simulations conceptualized at different, typically lower, scales, but direct coupling between models at different scales is in general prohibitive from computational point of view. An alternative implementation of the process coupling and parameters transfer involves the use of data driven surrogate models. In Prasianakis et al. (2020), the authors present an efficient way to transfer information between models across spatial scales using two examples. In the first example, they train a shallow neural network based on porosity permeability data produced from microscopic simulations, and integrate it in a Darcy-scale reactive transport code. In the second example, they train a neural network on geochemical speciation data produced from geochemical solvers adapted to the needs of a lab-on-a-chip microfluidic experiment. The reactive transport simulation benchmarks show that neural network models perform better than full speciation reactive transport simulations and look up tablebased approaches in terms of computational efficiency and memory requirements.

We are confident that with this special issue the readers of GCA will realize that the knowledge generated from multiscale simulations is of great value, and thus we expect these approaches will play important roles in geochemistry in the future.

\section{ACKNOWLEDGMENTS}

We are grateful to the Editors-in-Chief of GCA, Prof. Marc Norman, Prof. Jeff Catalano, as well as to Lisa Lovheim, Journal Manager, for their support to this special issue. We thank both authors and reviewers for their contributions.

\section{REFERENCES}

Bylaska, E.J., Song, D., Rosso, K.M., 2020. Electron transfer calculations between edge sharing octahedra in hematite, goethite, and annite. Geochimica et Cosmochimica Acta This issue.

Mei, Y., Liu, W., Brugger, J., Guan, Q., 2020. Gold solubility in alkaline and ammonia rich hydrothermal fluids: insights from ab initio molecular dynamics simulations. Geochimica et Cosmochimica Acta This issue.

Newton, A.G., Kwon, K.D., 2020. Classical molecular simulations of layered- and tunnel-structured manganese oxide minerals. Geochimica et Cosmochimica Acta This issue.

Prasianakis, N., Haller, R., Mahrous, M., Poonoosamy, J., Pfingsten, W., Churakov, S.V., 2020. Neural network based process coupling and parameter upscaling in reactive transport simulations. Geochimica et Cosmochimica Acta This issue.

Wang, K., Lu, X., Brodholt, J.P., 2020. Diffusion of noble gases in subduction zone 
hydrous minerals. Geochimica et Cosmochimica Acta This issue.

Zhang, Y., Liu, X., Zhang, C., Lu, X., 2020a. A combined first principles and classical molecular dynamics study of clay-soil organic matters (SOMs) interactions. Geochimica et Cosmochimica Acta This issue.

Zhang, Y., Liu, Y., 2020. How to produce isotope anomalies in mantle by using extremely small isotope fractionations: A process-driven amplification effect? Geochimica et Cosmochimica Acta This issue.

Zhang, Z., Csányi, G., Alfè, D., 2020b. Partitioning of sulfur between solid and liquid iron under earth's core conditions: constraints from atomistic simulations with machine learning potentials. Geochimica et Cosmochimica Acta This issue. 